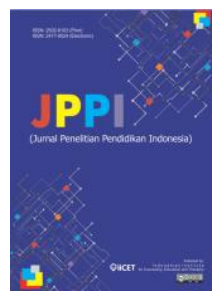

\title{
Kajian self adjustment pada mahasiswa kelas internasional
}

\author{
Puji Gusri Handayani ${ }^{\left.{ }^{*}\right)}$, Verlanda Yuca ${ }^{1}$, Hafiz Hidayat $^{1}$, Rezki Hariko $^{1}$, Rahmi Dwi Febriani $^{1}$ \\ ${ }^{1}$ Universitas Negeri Padang, Indonesia
}

\begin{tabular}{l}
\hline Article Info \\
\hline Articlehistory: \\
Received Mar $30^{\text {th }}, 2021$ \\
Revised Apr $02^{\text {nd }}, 2021$ \\
Accepted May $04^{\text {th }}, 2021$ \\
\hline
\end{tabular}

\section{Keyword:}

Self adjusment

Mahasiswa

Kelas internasional

\section{CorrespondingAuthor:}

Puji Gusri Handayani,

Universitas Negeri Padang

Email: pujigusrihandayani@gmail.com

\begin{abstract}
Penelitian ini bertujuan untuk menganalisis self adjustment pada mahasiswa dan menguji perbedaan self adjustment mahasiswa kelas internasional. Populasi dalam penelitian ini adalah 212 mahasiswa kelas internasional Universitas Negeri Padang, dengan menggunakan total sampling yaitu menggunakan seluruh mahasiswa kelas internasional. Metode penelitian menggunakan deskriptif komparatif. Instrumen yang digunakan adalah "Inventory Self Adjustment Puji and Verlanda" (ISAPUVE) dengan reliabilitas 0,80 . Kesimpulan dari penelitian ini adalah tidak terdapat perbedaan self adjustment mahasiswa laki-laki dan perempuan pada kelas internasional di Universitas Negeri Padang. Diharapkan UPBK (Unit Layanan Bimbingan dan Konseling) Universitas Negeri Padang memfasilitasi mahasiswa untuk dapat menekan self adjustment yang rendah melalui layanan yang tersedia di UPBK.
\end{abstract}

(C) 2021 The Authors. Published by IICET.

This is an open access article under the CC BY-NC-SA license

(https://creativecommons.org/licenses/by-nc-sa/4.0)

\section{Pendahuluan}

Perguruan tinggi di Indonesia memiliki peran untuk sumber daya manusia berupa ilmu pengetahuan, teknologi, terkhusus mahasiswa. salah satu peran perguruan tinggi dalam hal meningkatkan sumber daya manusia adalah menghasilkan dan menciptakan sumber daya manusia yang berkualitas melalui ilmu pengetahuan, teknologi dan sebagainya (Widiansyah, 2018). Dalam Undang-undang No. 12 Tahun 2012 pasal 4 dinyatakan bahwa Pendidikan Tinggi berfungsi: a) mengembangkan kemampuan dan membentuk watak serta peradaban bangsa yang bermartabat dalam rangka mencerdaskan kehidupan bangsa; b) mengembangkan sivitas akademika yang inovatif, responsif, kreatif, terampil, berdaya saing dan kooperatif melalui pelaksanaan Tridharma; dan c) mengembangkan Ilmu Pengetahuan dan Teknologi dengan memperhatikan dan menerapkan nilai humaniora. Sejalan dengan tujuan tersebut Universitas Negeri Padang (UNP) memiliki program untuk mewujudkan sumber daya manusia mahasiswa yang ditunggu-tunggu dan akan memiliki daya saing internasional. UNP memiliki kelas Internasional pada 14 jurusan dan program studi yang tersebar pada beberapa fakultas. Kelas internasional bertujuan untuk meningkatkan sumber daya manusia terutama dosen dan mahasiswa. UNP mulai merekrut mahasiswa yang mampu dan berminat belajar di kelas internasional sebagai wujud dari lulusan yang akan mempunyai daya saing di kancah internasional. Beberapa mahasiswa telah mengikuti program kelas international ini, tentunya dengan beberapa persyaratan. Namun, ada beberapa masalah yang menjadi persoalan dalam penyesuaian ketika mereka memasuki perguruan tinggi (Mesidor \& Sly, 2016). Gebhard (2012) mengungkapkan permasalahan yang dihadapi dalam self adjustment yaitu bidang akademik, interaksi sosial, dan emosional. Jika mahasiswa memiliki self adjustment yang baik, maka hasil belajarnya pun cenderung baik. Oleh karena itu, mahasiswa kelas 
internasional perlu memiliki self adjustment yang tinggi (da Costa et al., 2018). Selain itu, menurut (Mittelmeier et al., 2019) membuktikan bahwa self adjustment memiliki peran pada mahasiswa untuk dapat bertahan ketikaa berada dalam situasi sulit dan mempengaruhi kesuksesan mahasiswa.

Masalah yang dihadapi oleh mahasiswa internasional terletak pada penyesuaian sosial budaya seperti terjadinya culture shock pada mahasiswa rantau (Handayani \& Yuca, 2018), akademik (Afdhal, 2020) dan psikologis pribadi mereka (Mustaffa \& Illias, 2013). Penelitian menunjukkan mahasiswa internasional di Amerika mengalami hambatan bahasa dan budaya dalam interaksi sosial (Li \& Zizzi, 2018), perekrutan mahasiswa kelas internasional (Yabanova \& Özerbaş, 2020), dan kesehatan (Devors, 2017). Temuan di kelas internasional di Jurusan Bimbingan dan Konseling tahun 2017 dan 2018 menemukan bahwa 70\% mahasiswa tidak dapat berbahasa Inggris (Handayani \& Yuca, 2019), sehingga mereka merasa cemas ketika berdiskusi, mengerjakan tugas, dan situasi perkuliahan. Berry dalam Al Ariss (2010) menjelaskan bahwa self adjustment membutuhkan adaptasi terhadap kelompok minoritas. Spielberger (2004) menggunakan istilah adaptasi untuk merujuk pada konseptualisasi perubahan yang relatif stabil pada individu atau kelompok untuk merespon tuntutan dari luar dalam hal ini tuntutan kelas internasional. Proses tersebut dapat meningkatkan kecocokan antara individu dengan lingkungan. Secara umum self adjustment memiliki bentuk, yaitu; 1) Asimilasi: individu atau kelompok berubah lebih identik dengan lingkungannya (Maryono, 2020), 2) Pemisahan, individu atau kelompok berusaha mengubah lingkungan atau benar-benar menjauh dari lingkungan, 3) Akulturasi, jika mengalami kecocokan antara individu dengan lingkungannya (beradaptasi dengan baik), fenomena akulturasi stress ditemukan di dalam sekolah maupun perguruan tinggi yang mempunyai program kelas internasional (Sholehah et al., 2020). Berangkat dari uraian tersebut, melalui penelitian akan dikaji tentang self adjustment mahasiswa internasional laki-laki dan perempuan di UNP. Data yang diperoleh sangat bermanfaat bagi dosen penanggung jawab kelas internasional dan konselor dalam memberikan pelayanan konseling di UNP demi terwujudnya kehidupan sehari-hari yang efektif dan indeks prestasi yang tinggi.

Tujuan umum penelitian ini adalah (1) menganalisis self adjustment mahasiswa kelas internasional, dan secara khusus (2) menguji perbedaan self adjustment mahasiswa laki-laki dan perempuan kelas internasional. Penelitian mengenai self adjustment pada mahasiswa telah banyak dilakukan, namun yang menjadi kekhasan dalam penelitian ini adalah adanya UPBK (Unit Pelayanan Bimbingan dan Konseling) di perguruan tinggi yang selama ini belum menjadi prioritas.

\section{Metode}

Penelitian ini menggunakan metode kuantitatif dengan tipe deskriptif komparatif. Populasi penelitian ini menggunakan total random sampling yaitu menggunakan seluruh mahasiswa kelas internasional Universitas Negeri Padang yang berjumlah 212 mahasiswa. Instrumen yang digunakan adalah "Puji and Verlanda Self Adjusment Inventory" (ISAPUVE) dengan reliabilitas 0,80. Data dianalisis dengan statistik deskriptif dan komparatif.

\section{Hasil dan Pembahasan}

\section{Deskripsi Self adjustment}

Hasil penelitian pada Tabel 1 menunjukkan bahwa sebagian besar mahasiswa laki-laki internasional memiliki self adjustment dalam kategori sedang sebesar 37,63\% dan mahasiswa perempuan 37,8. Sedangkan 33,3\% mengalami self adjustment dalam kategori tinggi pada mahasiswa laki-laki, sedangkan pada mahasiswa perempuan 29,4\%, pada mahasiswa laki-laki 28\% mengalami self adjustment dalam kategori rendah dan untuk mahasiswa perempuan sebesar 31,1\%, pada mahasiswa laki-laki 1,07\% mengalami self adjustment dalam kategori sangat tinggi dan pada mahasiswa perempuan 1,7\%. Dapat disimpulkan bahwa rata-rata mahasiswa kelas internasional mengalami self adjustment dalam kategori sedang, baik mahasiswa laki-laki maupun perempuan.

Berada pada kategori sedang, hal ini dapat dipengaruhi oleh pendapat Schneiders (Gebhard, 2012) menjelaskan lima faktor yang mempengaruhi proses self adjustment yaitu: (a) Kondisi/fisik; (1) hereditas dan kondisi fisik, mengidentifikasi pengaruh hereditas terhadap self adjustment, menggunakan pendekatan fisik karena hereditas dianggap dekat dan tidak dapat dipisahkan dari mekanisme fisik, (2) sistem utama tubuh yaitu sistem saraf, otot, dan saraf , (3) kesehatan fisik, self adjustment individu akan lebih baik jika dalam kondisi sehat, (4) kepribadian, seperti; Kemauan dan kemampuan untuk berubah menjadi lebih baik (modifiability), regulasi diri, sangat mempengaruhi self adjustment untuk menjaga kestabilan mental dan mampu mengarahkan diri, realisasi diri, dalam proses self adjustment dan mencapai hasil sebagai wujud. 
Aktualisasi diri, kecerdasan, baik buruknya self adjustment individu juga dipengaruhi oleh kapasitas intelektualnya. (b) Proses Pembelajaran (Education); belajar, pengalaman, yang merupakan pengalaman yang menyenangkan dan traumatis, pelatihan, kebiasaan yang membuat Anda lebih terbiasa dan lebih bisa menyesuaikan diri dengan lingkungan. (c) lingkungan, faktor yang mempengaruhi budaya yaitu: lingkungan keluarga yang berperan penting dalam kaitannya dengan self adjustment, lingkungan sekolah merupakan tempat yang memungkinkan berkembang atau terhambatnya proses self adjustment, (lingkungan masyarakat, dimana terdapat sikap, nilai, norma, aturan, moral, dan perilaku yang akan mempengaruhi proses pengembangan self adjustment, budaya memberikan kontribusi penting terhadap perilaku individu untuk dapat melakukan self adjustment dimana individu tersebut berada.

Table 1. Distribusi Frekuensi Berdasarkan Kategori Skor Self Adjustment

\begin{tabular}{|c|c|c|c|c|c|}
\hline \multirow{3}{*}{$\begin{array}{c}\text { Skor Interval } \\
\text { Self Adjustment }\end{array}$} & \multirow[t]{3}{*}{ Kategori } & \multicolumn{4}{|c|}{ Self Adjusment } \\
\hline & & \multicolumn{2}{|c|}{ Laki-laki } & \multicolumn{2}{|c|}{ Perempuan } \\
\hline & & $\mathbf{F}$ & $\%$ & $\mathbf{F}$ & $\%$ \\
\hline $150-127$ & Sangat Tinggi & 1 & 1,07 & 2 & 1,7 \\
\hline $126-103$ & Tinggi & 31 & 33,3 & 35 & 29,4 \\
\hline $102-79$ & Sedang & 35 & 37,63 & 45 & 37,8 \\
\hline $78-55$ & Tidak Tinggi & 26 & 28 & 37 & 31,1 \\
\hline \multirow[t]{2}{*}{54} & $\begin{array}{c}\text { Sangat Tidak } \\
\text { Tinggi }\end{array}$ & - & - & - & - \\
\hline & & 93 & 100 & 119 & 100 \\
\hline
\end{tabular}

Menurut (Cai et al., 2017) self adjustment dapat dijelaskan dalam tiga aspek, yaitu: (1) diri individu, (2) orang lain, (3) dan terjadinya perubahan. Sejalan dengan pendapat tersebut, self adjustment pada dasarnya terdiri dari dua aspek, yaitu: (1) self adjustment, yaitu kemampuan individu untuk menerima diri sendiri untuk mencapai hubungan yang harmonis dengan lingkungan, (2) penyesuaian sosial, yaitu proses mempengaruhi. satu sama lain dalam berinteraksi dengan masyarakat. Sedangkan menurut (Gebhard, 2012) mengungkapkan self adjustment terdiri dari enam aspek; (1) kontrol emosi yang berlebihan, (2) mekanisme cacat minimal, (3) frustrasi individu minimal, (4) pertimbangan pemikiran rasional dan kemampuan mengarahkan diri sendiri, (6) kemampuan untuk belajar dan memanfaatkan pengalaman masa lalu, dan (7) ) kemampuan untuk bersikap realistis dan objektif.

Menurut (Walters \& Corey, 1980), ada beberapa faktor yang dapat memperbesar berbicara sosial yaitu: a) Kondisi fisik dan yang mempengaruhinya, mengatur keturunan, konstitusi Fisik, sistem saraf, tubuh dan tubuh, kesehatan, penyakit dan sebagainya, b ) Perkembangan dan kedewasaan, perluasan intelektual, kematangan sosial, moral dan emosional, c) Faktor psikologis, pengalaman, pembelajaran, kebiasaan, penentuan nasib sendiri, konflik dan konflik, d) Kondisi lingkungan, lingkungan rumah, keluarga dan sekolah, e) Budaya dan agama faktor. Faktor budaya juga diperkirakan berkontribusi terhadap percakapan sosial individu, karena latar belakang budaya mempengaruhi pembentukan, nilai, dan norma seseorang (Schneider, 1984). Individu yang akan hidup dalam suatu distribusi budaya tertentu akan mengadaptasi nilai-nilai sosial yang berasal dari lingkungan dan akan diterapkan dalam kehidupannya.

(Mesidor \& Sly, 2016) menyarankan sejumlah kriteria penyesuaian yang disesuaikan dengan baik yang ditandai dengan: (1) pengetahuan dan keterampilan menuju persahabatan, (2) penerimaan diri, (3) pengendalian diri, (4) integritas pribadi, (5) arah dan tujuan yang jelas, (6) skala nilai, cara pandang, dan falsafah hidup yang tepat dan memadai. juga mengungkapkan bahwa self adjustment yang baik adalah individu yang memiliki keterbatasan, kemampuan, dan kepribadian yang mampu belajar untuk bereaksi terhadap diri sendiri dan lingkungan secara efektif, efisien, berguna, dewasa, serta memuaskan.

Upaya self adjustment berjalan dengan baik dan juga kurang baik. Self adjustment yang baik memiliki ciriciri sebagai berikut; (1) diterima dalam kelompok, menerima kondisi diri yang baik berupa kelemahan dan kelebihan. Sementara itu, tidak adanya hubungan sosial individu merupakan tanda self adjustment yang buruk (Baba \& Hosida, 2014). Beberapa langkah efektif untuk menyesuaikan, antara lain; (1) realitas dengan persepsi yang akurat, (2) kemampuan menghadapi kecemasan dan stres, (3) memiliki citra diri yang positif, (4) mampu mengungkapkan perasaan, dan (5) memiliki hubungan interpersonal yang baik. 
Langkah pertama dalam proses self adjustment yang baik adalah pemahaman dan pengetahuan tentang diri sendiri. Setelah itu, langkah selanjutnya dalam self adjustment yaitu pengendalian diri yang dimaksud adalah individu mampu mengatur rangsangan, kemampuan berpikir, kebiasaan, emosi, dan perilaku yang berkaitan dengan prinsip dan norma yang dipakai untuk diri sendiri atau masyarakat (Mesidor \& Sly, 2016).

\section{Analisis Tes}

Berdasarkan Tabel 2, jika $\mathrm{F} \_$hitung $<0,05$ maka dapat dikatakan berbeda nyata, dari Tabel 2 diperoleh sebesar 0,636, artinya lebih besar dari 0,05 yang berarti tidak terdapat perbedaan self adjustment antara mahasiswa internasional laki-laki dan perempuan.

Table 2. Perbedaan Self-Adjustment Mahasiswa laki-laki dan Perempuan Kelas International

\begin{tabular}{cccccc}
\hline Self Adjustment & Jenis Kelamin & $\mathbf{N}$ & Mean & St. Deviation & F \\
\cline { 2 - 6 } & Laki-laki & 93 & 111,37 & 11,13 & 0,636 \\
& Perempuan & 119 & 113,03 & 13,25 & \\
\hline
\end{tabular}

Hipotesis ketiga, tidak ada perbedaan self adjustment mahasiswa antara laki-laki dan perempuan, hal tersebut terkait dengan teori gender. Sherif \& Trask (Samovar, L. A., Porter, R. E., McDaniel, E. R., \& Roy, 2010) menegaskan bahwa westernisasi dan globalisasi telah mempengaruhi semua keluarga secara berbeda berkaitan dengan masalah peran gender kepada anak-anak mereka. Oleh karena itu, tidak adanya perbedaan self adjustment mahasiswa laki-laki dibandingkan perempuan tidaklah mengherankan karena didukung oleh kesetaraan gender.

Kurangnya perbedaan self adjustment pada mahasiswa dapat disebabkan oleh teori gender, yaitu tentang kesetaraan gender. Di banyak masyarakat ada perbedaan antara anak laki-laki dan perempuan serta laki-laki dan perempuan dalam hal kesempatan, tanggung jawab, hak dan manfaat yang diberikan dan kegiatan mereka. Hasil penelitian ini didukung oleh pendapat (Raula \& Agustin Handayani, 2017) yang membuktikan bahwa tidak ada perbedaan self adjustment mahasiswa perempuan dan laki-laki.

Kesetaraan gender, atau kesetaraan antara laki-laki dan perempuan, mengacu pada kesetaraan hak, tanggung jawab, kesempatan, perlakuan, dan penilaian bagi laki-laki dan perempuan: 1) dalam pendidikan, 2) dalam pekerjaan, 3) dalam hubungan antara pekerjaan dan kehidupan. Kesetaraan gender berarti bahwa semua orang dari segala usia dan jenis kelamin harus memiliki kesempatan yang sama untuk berhasil dalam hidup. Artinya, semua manusia harus memiliki akses dan kontrol yang sama atas sumber daya dan manfaat, dengan kata lain secara adil, sehingga setiap orang dapat memperoleh manfaat dan berpartisipasi dalam pembangunan. Hal senada juga dibahas dalam penelitian (Handayani \& Yuca, 2018) bahwa tidak ada perbedaan antara culture shock mahasiswa perempuan dan laki-laki, culture shock disini erat kaitannya dengan bagaimana seorang mahasiswa mampu melakukan self adjustment di lingkungan baru. Senada dengan itu, (Hidayat \& Handayani, 2018) juga menjelaskan tidak ada perbedaan self-regulated learning siswa laki-laki dan perempuan. Tidak adanya perbedaan tersebut dipengaruhi oleh jenis kelamin.

Selain gender salah satu yang mempengaruhi tidak terdapatnya perbedaan self adjustment mahasiswa lakilaki dan perempuan adalah teman sebaya dalam lingkungan sosial (Sasmita \& Rustika, 2015). Teman sebaya berperan sebagai sumber dukungan emosional dalam kehidupan mahasiswa yang bertransisi pada masa remaja, hal itu disebabkan oleh intensitas waktu dengan teman lebih banyak dibandingkan dengan yang lain. Dukungan yang diberikan berupa kenyamanan psikologis sehingga inidividu akan mudah untuk diterima, beradaptasi dari kelompok sosialnya (Rufaida \& Kustanti, 2017).

\section{Simpulan}

Berdasarkan hasil penelitian, diperoleh dalam penelitian ini, dimana analisis statistik dan pengujian hipotesis telah dilakukan dan di ulas serta dijabarkan dalam pembahasan, maka dapat disimpulkan sebagai berikut; (1) Self adjustment mahasiswa laki-laki dan perempuan kelas internasional dalam kategori sedang, (2) tidak ada perbedaan self adjustment mahasiswa laki-laki dan perempuan di kelas internasional dengan menunjukan hasil $F_{\text {Hitung }}$ sebesar 0,636 yang berarti tida terdapat perbedaan.

Diharapkan pihak universitas memberikan pembekalan kepada mahasiswa baru khususnya dalam hal self adjustment di lingkungan kampus dan masyarakat khususnya bagi mahasiswa yang akan memasuki kelas internasional.

Berada pada kategori sedang bermakna bahwa self adjustment memerlukan penaganan oleh konselor universitas. Di Universitas Negeri Padang memiliki Unit Pelayanan Bimbingan dan Konseling (UPBK) yang 
dibisa dimanfaatkan untuk mengatasi permasalahan self adjustment mahasiswa. Diharapkan UPBK (Unit Layanan Bimbingan dan Konseling) memfasilitasi mahasiswa untuk dapat menekan self adjustment yang rendah yang terjadi pada mahasiswa melalui layanan yang tersedia di UPBK, yaitu layanan konseling individu, layanan bimbingan kelompok, layanan konseling kelompok, layanan informasi, layanan orientasi, dll.

\section{Referensi}

Afdhal, Y. (2020). Pengaruh Motivasi Berprestasi dan Stres terhadap Prestasi Akademik Mahasiswa Tahap Akademik Kelas Internasional Program Studi Pendidikan dan Profesi Dokter Fakultas Kedokteran Universitas Indonesia. IMPROVEMENT: Jurnal Ilmiah Untuk Peningkatan Mutu Manajemen Pendidikan, 7(02), 100-110. http://journal.unj.ac.id/unj/index.php/improvement/article/view/18366

Al Ariss, A. (2010). Modes of engagement: Migration, self-initiated expatriation, and career development. Career Development International, 15(4), 338-358. https://doi.org/10.1108/13620431011066231

Cai, V. A. D., Bidaud, P., Hayward, V., \& Gosselin, F. (2017). Self-adjustment mechanisms and their application for orthosis design. Meccanica, 52(3), 713-728. https://doi.org/10.1007/s11012-016-0574-0

da Costa, A., Hanurawan, F., Atmoko, A., \& Hitipeuw, I. (2018). the Impact of Self-Adjustment on Academic Achievement of the Students. ISLLAC : Journal of Intensive Studies on Language, Literature, Art, and Culture, 2(1), 1-6. https://doi.org/10.17977/um006v2i12018p001

Devors, J. (2017). International Student Struggles. May, 2009-2014. https://www.researchgate.net/publication/320765245_International_Student_Struggles

Gebhard, J. G. (2012). International_Students_Adjustment_Proble Genhard. Journal International Student, 2(2).

Handayani, P. G., \& Yuca, V. (2018). Fenomena Culture Shock Pada Mahasiswa Perantauan Tingkat 1 Universitas Negeri Padang. Jurnal Konseling Dan Pendidikan, 6(3), 198. https://doi.org/10.29210/129000

Handayani, P. G., \& Yuca, V. (2019). Kontribusi Culture Shock Terhadap Self Adjustment. Neo Konseling, 1(3), 3-8. https://doi.org/10.24036/00190kons2019

Hidayat, H., \& Handayani, P. G. (2018). Self Regulated Learning (Study for Students Regular and Training). Jurnal Penelitian Bimbingan Dan Konseling, 3(1), 50-59. https://doi.org/10.30870/jpbk.v3i1.3196

Li, S., \& Zizzi, S. (2018). A case study of international students' social adjustment, friendship development, and physical activity. Journal of International Students, 8(1), 389-408. https://doi.org/10.5281/zenodo.1134317

Maryono, M. (2020). Proses Berpikir Mahasiswa dalam Menyelesaikan Masalah Berstandar PISA (Programme for International Student Assesment). Journal of Education and Learning Mathematics Research (JELMaR), 1(1), 1-14. https://doi.org/10.37303/jelmar.v1i1.1

Mesidor, J. K., \& Sly, K. F. (2016). Factors that contribute to the adjustment of international students. Journal of International Students, 6(1), 262-282.

Mittelmeier, J., Rogaten, J., Long, D., Dalu, M., Gunter, A., Prinsloo, P., \& Rienties, B. (2019). Understanding the early adjustment experiences of undergraduate distance education students in South Africa. International Review of Research in Open and Distance Learning, 20(3), 19-38. https://doi.org/10.19173/irrodl.v20i4.4101

Mustaffa, C., \& Illias, M. (2013). Relationship between students adjustment factors and cross cultural adjustment: A survey at the Northern University of Malaysia. Intercultural Communication Studies, 1(22), 279-300.

Raula, U., \& Agustin Handayani. (2017). Penyesuaian Diri Mahasiswa Luar Jawa Ditinjua dari Persepsi Lingkungan dan Jenis Kelamin. Journal of Chemical Information and Modeling, 53(9), 1689-1699. file:///C:/Users/User/Downloads/fvm939e.pdf

Rufaida, H. R., \& Kustanti, E. R. (2017). Hubungan Antara Dukungan Sosial Teman Sebaya Dengan Penyesuaian Diri Pada Mahasiswa Rantau Dari Sumatera Di Universitas Diponegoro. Empati, 6(3), 217222.

Samovar, L. A., Porter, R. E., McDaniel, E. R., \& Roy, C. S. (2010). Communication Between Cultures Boston. .MA: Wandworth, Cengage Learning.

Sasmita, I. A. G. H. D., \& Rustika, I. M. (2015). Peran Efikasi Diri dan Dukungan Sosial Teman Sebaya Terhadap Penyesuaian Diri Mahasiswa Tahun Pertama Program Studi Pendidikan Dokter Fakultas Kedokteran Universitas Udayana. Jurnal Psikologi Udayana, 2(2), 280-289. https://doi.org/10.24843/jpu.2015.v02.i02.p16

Sholehah, M., Fitri, S., \& Fridani, L. (2020). Akulturasi Stress Siswa Mutasi dari Sekolah di Luar Negeri. Indonesian Journal of Educational Counseling, 4(1), 85-94. https://doi.org/10.30653/001.202041.98

Walters, L. H., \& Corey, G. (1980). Theory and Practice of Counseling and Psychotherapy. Family Relations, 29(1), 133. https://doi.org/10.2307/583738 
Widiansyah, A. (2018). Peranan Sumber Daya Pendidikan sebagai Faktor Penentu dalam Manajemen Sistem Pendidikan. Manajemen Sistem Pendidikan. Cakrawala, 18(2), 229-234. http://ejournal.bsi.ac.id/ejurnal/index.php/cakrawala

Yabanova, U., \& Özerbaş , D. H. (2020). International Student Selection Process in Turkey: Characteristics, Challenges and Opportunities. International Journal of Progressive Education, 16(2), 137-156. https://doi.org/10.29329/ijpe.2020.241.10 